\title{
Erratum to: A New Approach: Resection and Suture of Orbicularis Oculi Muscle to Define the Upper Eyelid Fold and Correct Asymmetries
}

Claudio Bas Thomas · Joaquín Pérez-Guisado

Published online: 14 December 2012

(C) Springer Science+Business Media New York and International Society of Aesthetic Plastic Surgery 2012

Erratum to: Aesth Plast Surg

DOI 10.1007/s00266-012-9953-7

The correct name of the first author is Claudio Bas

Thomas.

The online version of the original article can be found under doi:10.1007/s00266-012-9953-7.

C. B. Thomas

Sara Moncada Clinic, Av. Pedro de Valdivia 2219, Providencia,

Santiago de Chile, Chile

e-mail: claudiothomas@123.cl

J. Pérez-Guisado $(\square)$

Service of Plastic, Aesthetic and Reconstructive Surgery,

Reina Sofía University Hospital, Av. Menéndez Pidal s/n,

14004 Córdoba, Spain

e-mail: pv1peguj@uco.es 